\title{
The Reality of Improving the Governing Ability of Rural Grassroots Cadres
}

\author{
Zhenliang Yan* \\ Jiangsu Police Officer College, Nanjing 210000, Jiangsu Province, China \\ *Corresponding author: Zhenliang Yan, yanzhenliang@jspi.edu.cn
}

\begin{abstract}
The countryside is the fundamental unit of society, the base for innovative social government, and an important cornerstone for the party's ruling foundation. Based on this, this article proposes some ideas and exploration on increasing the governance capacity of rural grass-roots cadres in order to satisfy the demands of constructing a socialist modern nation.
\end{abstract}

Keywords: Rural; Cadres; Government

Publication date: December 2021; Online publication: January 24, 2022

\section{Introduction}

Villages take on the important task of development in order to build a modern socialist country from the ground up. With China's continued urbanization and gradual growth of urban size, deep changes in urban and rural social structure have occurred, and issues such as extended management mode and inadequate information transmission in rural governance have become more important. How to effectively respond to and actively deal with new challenges and problems in the process of urban development, properly resolve prominent contradictions and deep-seated problems limiting the governance efficiency of urban and rural communities, and put forward higher requirements for the governance ability of rural basic cadres, has also become a realistic subject that needs to be solved urgently ${ }^{[1]}$.

\section{The status and role of rural governance in the new era are becoming increasingly prominent}

\subsection{Rural governance is the core pillar of national governance}

The Chinese people have evolved from unit people to family people, community people, and social people as a result of the market-oriented transformation. Individuals and family locations are the main body of national government, which has shifted from units to villages and communities. Villages have evolved into the most grassroots level of government. In recent years, the state has put up a number of significant laws and governance theories, including doing a good job in grassroots basic management and stabilizing the foundation in order to assure the country's general growth. In the new era, the focus of social governance should be on rural infrastructure construction. Through the implementation of corresponding measures to improve rural services and management capacity, we can effectively promote the development of social construction. From the analysis of these arguments, it is not difficult to see that the current urban and rural community governance represents an important position in the new era and fully reflects it.

\subsection{Rural governance is the key field of county (district) social governance}

County (district) social governance is an important direction of social governance in China. Adhering to people-centered is the starting point and foothold of county (district) social governance. In the process of 
promoting the modernization of county (district) social governance, all localities have accelerated the construction of urban and rural service management system to meet the needs of people's better life, and formed distinctive rural governance models.

First, the government led model. The characteristic of this model is to empower the town (street), clarify the street, and shift the focus of work to social governance. This model is conducive to the uniform distribution of resources in the streets, but it is highly dependent on finance and is not easy to be popularized in areas with backward economic development level.

The second is the model of social autonomy ${ }^{[2]}$. The characteristic of this model is to establish a new autonomous organization on the basis of the original organizational system and promote the improvement of the system of rural democratic autonomy.

In rural areas, the leadership is the rural party organization. The decision-making level is the village member congress. The executive level is the village committee, and a new team is formed by the recruitment and selection personnel and management departments. The deliberative level is the village committee, which is composed of deputies to the people's congress and residents' representatives in the village, and then supervises the actual work within the neighborhood committee. This model needs to rely on government departments to gradually play a democratic role.

\subsection{Rural governance is a key link in building a pattern of co-construction, co-governance, and shared grassroots governance}

Creating a new governance pattern is not only an important embodiment of complying with the development of the times, but also the key to giving back to the actual needs of residents and creating a new institutional system.

Pluralistic co-governance is the first step. In the new era, urban and rural community governance must begin with the current situation, establish a classified governance system, and clarify governance subjects' rights and responsibilities. Among these, appropriate government departments manage "big events" of public services, party and social groups handle "minor events" of rural services, and the community neighborhood committee handles "private affairs" of residents. As a consequence, an urban and rural governance pattern emerges in which the government, villages, social groups, social workers, and inhabitants work together to govern.

In terms of resource allocation, the shared resource allocation structure is used to bridge the gap between communities in terms of public resources and to aid in the equalization of public services. In terms of governance tools, we have established a network relationship between multiple governance subjects, unblocked the channels of communication and appeal expression for residents, accurately connected with their living needs, and promoted the efficient operation of community governance with the help of the Internet and big data technology ${ }^{[3]}$.

Third, promote autonomy. In the new era of rural governance, it is necessary to promote the restoration of the village (neighborhood) committee's roles, including disseminating rules and regulations, carrying out good unneighborly activities, leading public welfare initiatives, and overseeing property management. The village (neighborhood) committee elects its members, actively provides a platform for rural governance involvement, and directs the backbone of people to evolve into the backbone of promoting autonomy.

\section{Shortcomings of village cadres in the process of rural governance}

Rural cadres have achieved the growth of their own potential via the process of rural government, which has added incalculable value to economic and social development. However, there is still a gap between rural cadres' governance capacity and expectations in the process of rural government in practice. People 
of higher quality and ability must engage in all aspects of life, whether it is to direct people's lives or to improve communal activities. The primary ability of the community is connected to the effectiveness of community governance and development. The lack of a long-term method to increase numerous subjects' governing capacity has become a pressing issue that must be addressed.

\section{The posts of community workers change frequently and the capacity-building is not systematic}

In addition to the real situation, some urban communities have a significant workload, with no defined division of responsibilities or judging criteria for detailed work. Personnel assigned to a task, for example, must accomplish related work, and their professional skill is typically insufficient. "Well done" has been pushed in the absence of a professional training mechanism and a planned training scheme. It is unquestionable that practically all community workers want to get rid of the dual pressure of superior organizations and grass-roots individuals. It is impossible to truly increase the level and quality of service when many community employees mindlessly follow the herd to pursue their own interests and personal growth. Some community employees lack a strong feeling of service and do not pay enough attention to community development due to a lack of incentive and punishment mechanisms. There is a scenario in which fishermen are fishing in difficult seas, and many laws and regulations are unable to be enforced in certain situations. This condition creates significant barriers to the development of both urban and rural populations.

\section{Grassroots society generally lacks channels of participation, making it difficult to reach a broad consensus}

The link connection governed by patriarchal clan system and kinship has eroded since the post-unit era, and people have become scattered and autonomous individuals. Some residents simply see the neighborhood as a place to live and have no desire to participate in community governance. Some demonstrate pluralistic co governance, which is actually "mobilized participation" and "passive participation" under the party and government's leadership. This indicates that various inhabitants have varied interests and psychological obstacles, therefore they are less motivated to engage in community development. Even if some residents are enthusiastic about community affairs, residents will find it difficult to provide timely and effective feedback on the relevant measures implemented due to a lack of smooth communication channels, which will not only undermine residents' enthusiasm for participation in governance, but also call into question the government's and neighborhood committees' credibility. Furthermore, according to the analysis of relevant survey data, the management scope of some community neighborhood committees now often includes multiple property companies, and due to the characteristics of many and varied personnel in the community, there is often work exclusion between multiple property departments, and many property companies do not fully gain the recognition and trust of residents.

\section{There is "quantity" and "quality" gaps between the quality and ability of the governance subject and the population base and service scope}

The government will buy some public services on the open market and distribute them to the public, such as community pensions and childcare. However, grass-roots government's service delivery is based on the "bureaucracy" system, which offers public services to society as a passive executor, making it impossible for grass-roots government to understand community residents' true needs. Neighborhood committees have long modified their operating manner of interacting with everyone every day in order to increase their sentiments. They spend the bulk of their time and energy accomplishing or even dealing with their superiors' inspections and supervision, and so they do not have enough time or energy to truly communicate with the 
majority of residents. The system of public services will inevitably be fragmented. In terms of social organizations, they can only develop in the existing institutional environment if they are linked to the government, ensuring that the behavioral incentive of social organizations always aligns with the government's goals. Furthermore, the community's service function focus is harmed by the lack of related organizational norms and technological standards. The services provided by property companies are similar to or overlap with those provided by neighborhood committees, including basic greening, property facility management, and basic owner requirements, in order to provide them with more standardized and scientific management services in combination with these contents. Furthermore, because the service contents between the community neighborhood committee and the property company are essentially the same, the two departments are "almost the same" in management, making it extremely easy to compete for responsibilities, and the relationship between the two cannot be well coordinated, indicating that the current community management planning for public unity is not clear to some extent.

\section{Suggestions on focusing on team quality and improving the governance ability of grassroots cadres}

In rural areas, there are various complex factors such as multiple subjects, multiple matters, and multiple contradictions. Various social diseases are highlighted and upgraded, and various governance risks and crises are intertwined. There is an urgent need to improve the governance capacity-building of grassroots managers, which is the essence of rural revitalization.

\subsection{Party member team}

The county (district) should build party organizations in all of its grids, give full play to grid party organizations' leading core role in rural (neighborhood) government, and extend the party's leadership to the end of social governance. Encourage grassroots party members to serve as full-time and part-time grid members, incorporate retired elderly party members into the part-time grid team, take the lead in urban and rural community government, and mobilize the people to engage in co-governance. Attract members of the grid's "night patrol," as well as volunteers and activists with working abilities, to engage in the grid's "night patrol" and gather joint governance efforts.

\subsection{Grid member team}

According to the " $1+4+\mathrm{X}$ " paradigm, each grid has a grid leader, a social management informant, a contradiction and conflict mediator, and so on. Recruit grid members through street recruiting, rural recruitment, job transfers among members of the urban management team, and other methods. Improve the six grid service systems, clarify the 84 items in 15 grid patrol categories, and increase the pertinence and efficacy of patrol. Organize all full-time grid staff to engage in training and increase their capacity to detect and solve problems, as well as their professional and professional level, by establishing a grid college or cooperating with colleges and universities.

\section{Funding}

General Project of Philosophy and Social Sciences Research of Jiangsu Police Officer College (Project Number: 2020sjys06).

\section{Disclosure statement}

The author declares that there is no conflict of interest. 


\section{References}

[1] Wang D, 2018, Urban Social Transformation and Construction of Community Governance System. Political Science Research, (5): 6-9.

[2] Li J, 2018, Countermeasures to Solve the Anxiety of Middle-Income Groups. Social governance, (8): 70-74.

[3] Jiang Q, 2010, Optimization of "Trinity" Management Model of Urban Community. Development Research, (6): 84-87. 